\title{
Compressive Strength of Stripes and Flakes of Recycled Polyethylene Terephthalate (PET) Added Concrete
}

\author{
IMRE KISS ${ }^{1 *}$, ANDREI MIHAI BACIU ${ }^{2}$, ILARE BORDEASU ${ }^{3 *}$, \\ LAVINIA MADALINA MICU ${ }^{4 *}$ \\ ${ }^{1}$ University Politehnica Timisoara, Faculty of Engineering Hunedoara, Department of Engineering \& Management, \\ 5 Revolutiei, 331128, Hunedoara, Romania \\ ${ }^{2}$ University Politehnica Timisoara, Faculty of Engineering Hunedoara, Center for Research in Advanced Materials \& \\ Technologies, 5 Revolutiei, 331128, Hunedoara, Romania \\ ${ }^{3}$ University Politehnica Timisoara, Faculty of Mechanical Engineering, 1 Bd. Mihai Viteazu, 300222,Timisoara, Romania \\ ${ }^{4}$ University of Agricultural Sciences and Veterinary Medicine of Banat King Mihai I from Romania, 119 Calea Aradului, \\ 300645, Timisoara, Romania
}

\begin{abstract}
The wastes from polyethylene terephthalate (PET) packaging can be turned into armatures for concrete used in the transports infrastructure (roads with rigid concrete structure, pedestrian and concrete pavements and borders), as well as in the construction of safety elements (support walls, bulwark foundations). This experimental research was meant to create dispersed reinforced concrete with armatures from polyethylene waste, originated from the recycling programmes of PET-type packaging. The experimental programme was aimed at constructing some samples of dispersed reinforced concrete from recycled material coming from polyethylene terephthalate (PET) packaging wastes, their testing to the compressive strength and the comparison of results with the characteristics of the standardised samples of concrete (class C30/37). All the reinforcements used in this work to consolidate the dispersed reinforced concrete type were made from a mix of polyethylene terephthalate (PET) packages, of different types and characteristics, which are found daily in supermarkets and which then reach waste. The choice of a mix of polyethylene terephthalate (PET) packaging was chosen in order to render the general recycling of these types of materials as good as possible.
\end{abstract}

Keywords: polyethylene terephthalate PET-type packaging, dispersed reinforcement concrete, PET flakes (flat strips, chips), compressive strength

\section{Introduction}

Concrete is one of the most widely-used materials in the construction industry, due to the continuous adaptability as well as the high performance obtained throughout the years [1,2]. This material was and it is still used in building infrastructure, massive structures, high constructions, industrial, cultural or sports constructions etc. The concrete is a composite construction material obtained through the hardening of the homogenous mixtures of aggregates, binders and water (Figure 1) [3-6]. The mixture of binder and water forms a plastic paste which, by hardening, binds the aggregate granules (it conveys mechanical tension between the granules), rendering the concrete its monolith character, transforming into a rigid solid version of itself with a higher mechanical resistance (Figure 2). The aggregates, which take approximately $80 \%$ of the volume of concrete, making up its rigid skeleton, by their properties, they influence decisively the durability and performance of concrete, including its resistances to compression, stretch and abrasion $[2,3,5,7]$.

\footnotetext{
*email:imre.kiss@upt.ro,ilarica59@gmail.com,lavimicu@yahoo.com
} 

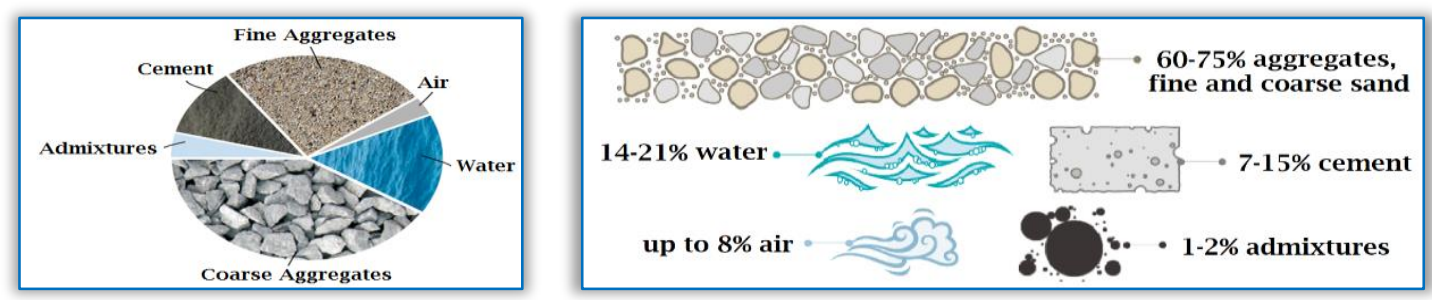

Figure 1. Concrete usual recipe
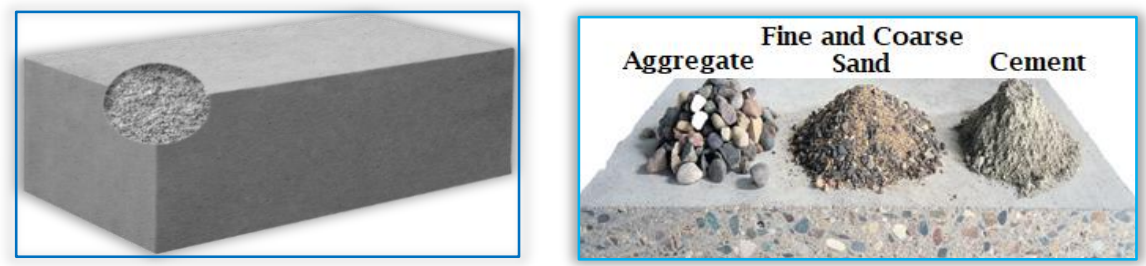

Figure 2. Solid factions of the concrete recipe

The concrete with dispersed reinforcement represents a generation of reinforced concrete, which combines the compression behaviour of the concrete with the good tensile behaviour of the reinforcement. Fibre-reinforced concrete results by addition in the concrete mass of a certain amount of staple fibre that can be obtained from steel, glass, polymers or other materials $[1,8,9]$. The great variety of composite materials resulted by combining different types of reinforcement has been the subject of many studies and researches [10-15].

Regarding the systematic researches in the field of reinforced concrete dispersed with polyethylene fibres, it can be said that they are still in a less developed stage. Concrete with dispersed reinforcement (Figure 3) is one of the ways to maintain the competitiveness of the concrete as one of the main building materials. The opportunity to use fibre reinforcement appears in the situation of using a small percentage of reinforcement or in the case of constructive reinforcement of ordinary reinforced concrete. In reinforcing concrete, fibres are increasingly used because they provide control of the cracking process and increase the resistance to impact, shocks and temperature variations $[1,8,9,16-$ 19].
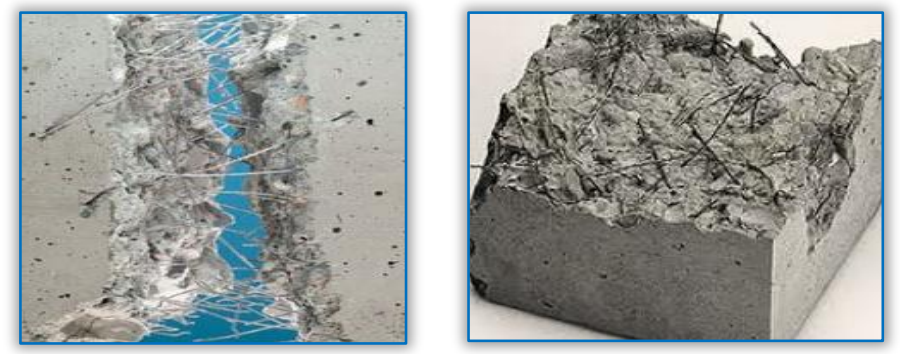

Figure 3. Concrete with polymer reinforcement

\section{Materials and methods}

Concrete with dispersed reinforcement is a concrete, which contains in composition, in addition to the conventional components of an ordinary concrete (mineral binder - cement, aggregates, water, additives), and quantities of dispersed material. The present work refers to the concrete in which the dispersed reinforcement is made of polymeric materials.

Non-reinforced concrete (class C30/37) and reinforced concrete dispersed with reinforcements from polyethylene terephthalate (PET) waste were made in laboratory conditions, on an exact recipe and in accordance with the norms in force. Non-reinforced concrete (class C30/37) is based on the following materials: water, Portland cement, sand (sort 0-4 mm) and gravel (sorts 4-8 $\mathrm{mm}$ and 8-16 
$\mathrm{mm}$ ) and additives, in proportion of about $77 \%$ aggregate, $15 \%$ cement and $8 \%$ water. When preparing the concrete, the mixing of the components ensured a good homogeneity of the concrete and the dispersion of the cement, favouring hydration.

The concrete used in all the samples, for all the reinforcement modes and for the concrete samples, was one and the same, from the same preparation batch, with the same characteristics. In this way, the influence of the reinforcements on the compression characteristics of the analysed concrete was followed.

All the reinforcements used in this work to consolidate the ceramic composite materials - dispersed reinforced concrete type - were made from material from a mix of polyethylene terephthalate (PET) packages, of different types and characteristics, which are found daily in supermarkets and which then reach waste. The choice of a mix of polyethylene terephthalate (PET) packaging was chosen in order to render the general recycling of these types of materials as good as possible.

a)

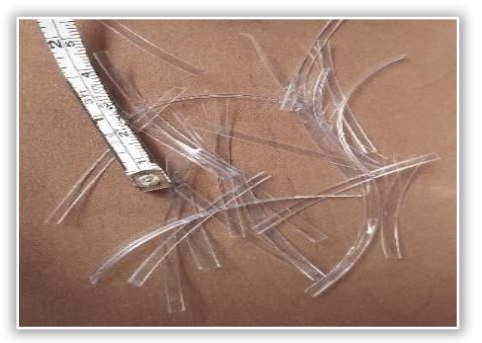

Figure 4. Preparing the PET reinforcement: a) PET flat strips; b) PET chips

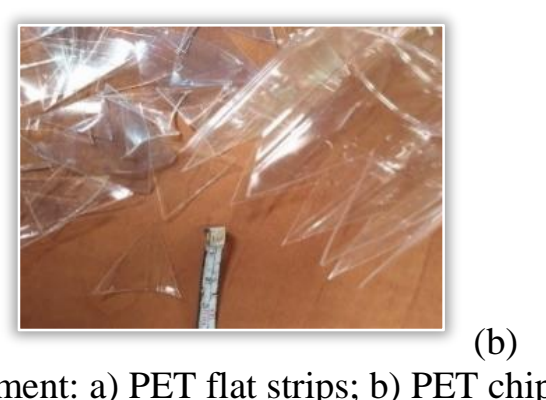

(b)

In the first of the reinforcement methods, the extraction of flat strips from polyethylene terephthalate (PET) packaging was chosen. (Figure 4.a) The second reinforcement method uses reinforcements in the form of chips from polyethylene terephthalate (PET) packaging (Figure 4.b).

The technological processes for the preparation of concrete with dispersed reinforcement do not differ substantially from the conventional procedures; they require additional equipment only for dosing the dispersed reinforcement. For the production of quality concrete, using quarry and pit aggregates, the quality conditions were respected compared to the component materials and the principles specific to each technological stage $[1,8,9]$. All additives were dosed and used according to the provisions of their technical data sheets issued by the manufacturers. The preparation of the concrete with dispersed fibres implies:

- dosing of the concrete components (types of dry aggregates and cement) and primary mixing,

- dosing and adding of water and additive, continuing the mixing as with any concrete.

- making reinforcement of concrete, by pouring concrete into formworks and subsequently adding the dispersed polymer reinforcement, in a stratified way.

The strength of the concrete depends, first of all, on the density, which is evidenced by a small volume of pores and which gives the concrete the possibility to withstand the attack of aggressive substances. It is possible to obtain an appreciable resistance to corrosion through a carefully made, well compacted concrete. The determination of the volumetric mass (density) is made according to [20-23]. The norms in force, elaborated on the basis of the in-depth knowledge of the influence of the components on the properties of the concrete, of a long experience regarding its technology, specify the way in which the composition of the concrete is established, on the basis of the principle of maximum compactness, so that it corresponds to the quality conditions imposed. The volumetric mass of the concrete provides useful information on the composition, especially during the control of the concrete production, being able to signal, operatively, certain errors of dosage of the components if it is determined systematically. It is expected that the determined value of the concrete density of class $\mathrm{C} 8 / 10-\mathrm{C} 35 / 45$ will be in the range $2200-2400 \mathrm{~kg} / \mathrm{m}^{3}$. 
Compressive strength is one of the main criteria for assessing the quality of a concrete. The determination of the compressive strength of the reinforced concrete (at 28 days) is determined according to [24] and [25], based on the test carried out on a minimum number of three samples of cubic form (cubic strength).

\section{Experiments}

\section{Making of reinforcements}

The polyethylene terephthalate PET flat strips made from the threads extracted from polyethylene terephthalate (PET) bottles were cut to the required dimensions (with approximate sides of $0.5 \times 10 \mathrm{~cm}$ ), after which they were weighed for the 15 grams (about $1.5 \%$ of the reinforced concrete component, experiment no.2), requiring about 300 pieces (Figure 5.a).

For the $15 \mathrm{~g}$ of chips used for reinforcing the specimen (about $1.5 \%$ of the reinforced concrete component, experiment no.3), on average, 70 pieces of polyethylene terephthalate (PET) chips, made by cutting from the polyethylene terephthalate (PET) containers, in triangular form (with approximate sides of $3 \times 3 \times 3 \mathrm{~cm}$ ) were required (Figure 5.b).

a)

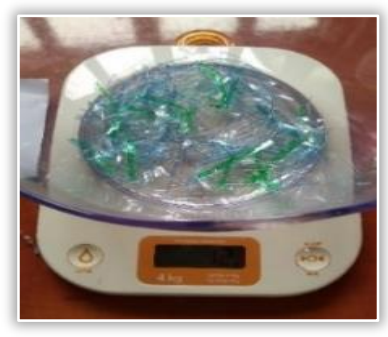

Figure 5. Weighing of the PET flakes reinforcement:

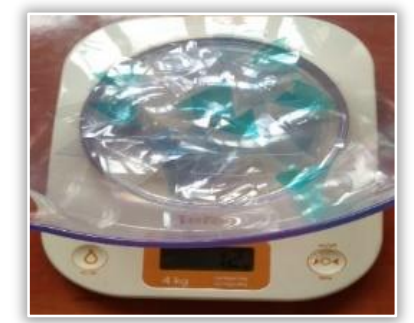

(b)

a) PET flat strips; b) PET chips

\section{Making the concrete samples}

Special formworks were prepared for the samples to be made and they were emulsified with special oil for easy subsequent stripping (Figure 6). After the realization of the concrete class C30/37, it was poured as a concrete sample, considered as the standard sample. The vibrating mass ensured the homogenization and elimination of the casting holes in the tubes. After completion, the samples were properly labelled so that they could be easily identified at the time of testing (Figure 6). The day after the casting the samples were stripped and kept in laboratory conditions for 28 days until the concrete maturation.
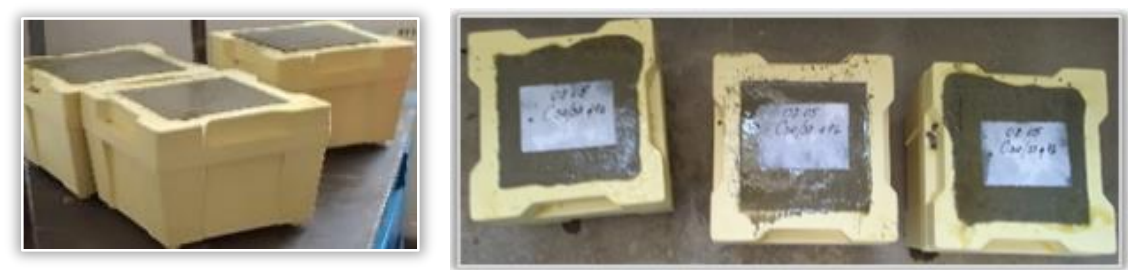

Figure 6. Preparing and labelling the concrete samples

\section{Making the samples reinforced with PET flat strips}

Special formworks were prepared for the samples from the second experiment (experiment no. 2, Figure 7.a). The entire matrix assembly and the polyethylene terephthalate (PET) flat strips reinforcement were constantly vibrated on the vibrating table to ensure a correct homogenization of the concrete and to make compact samples without casting holes. After completion, the samples were labelled (Figure 8.a). The next day the specimens were stripped and then kept in optimum conditions in the specialized laboratory for 28 days for the proper maturation of the concrete, necessary for carrying out the laboratory tests. 


\section{Making the samples reinforced with PET chips}

Special formworks were prepared for the samples from third experiment (experiment no. 3, Figure 7.b). The cast of concrete matrix and polyethylene terephthalate (PET) chips reinforcements is performed on a vibrating table and under optimal laboratory conditions for results conforming to the norms and standards in force. After proper casting and vibration of the samples, they were labelled accordingly to be easily and correctly identified at the time of the laboratory tests (Figure 8.a). The next day, the specimens were stripped and then kept in optimal conditions in the specialized laboratory for 28 days for maturation (Figure 8.b).

(a)

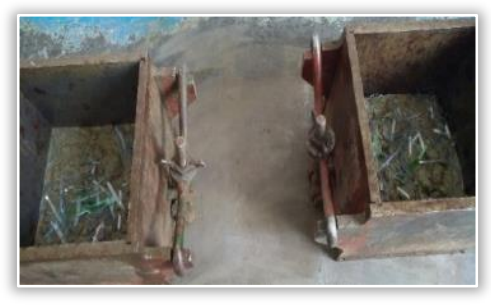

Figure 7. The PET flakes reinforcing process:

a) with PET flat strips; b) with PET chips

(a)
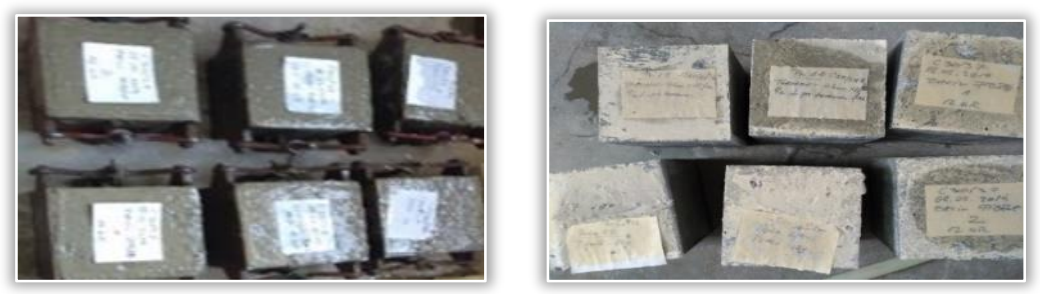

Figure 8. Labelling the reinforced concrete samples

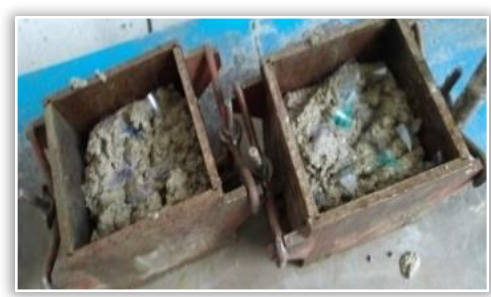

(b)

(b)

\section{Results and discussions}

After the 28 days necessary to achieve the maturation of all the specimens (all cast simultaneously in formworks and matured under the same conditions) and weighing of the concrete samples (Figure 9) it is possible to proceed to the accomplishment of the laboratory loads. The UTest-Autocon testing equipment was used to determine the compression load (Figure 10 and Figure 11). All the experimental values are presented in Table 1.

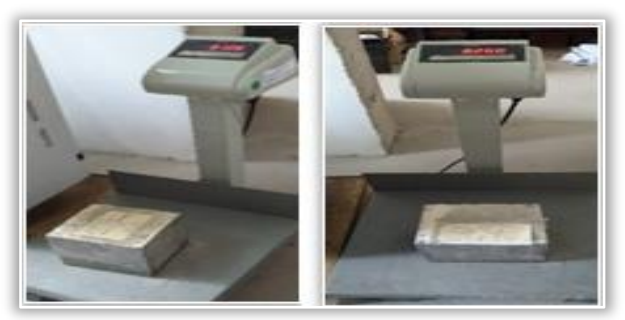

Figure 9. Weighing of the concrete samples

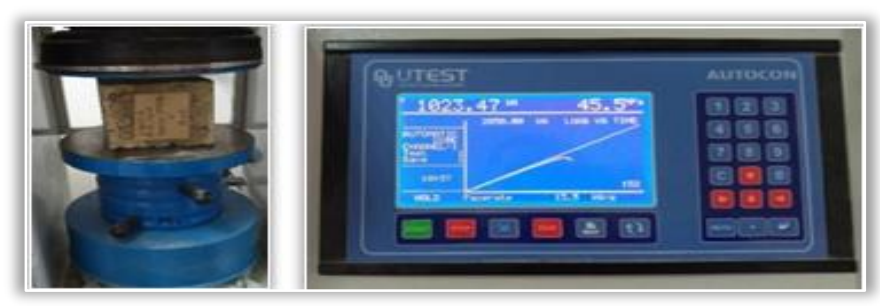

Figure 10. Compression strength test of with PET flat 
strips' reinforced concrete samples

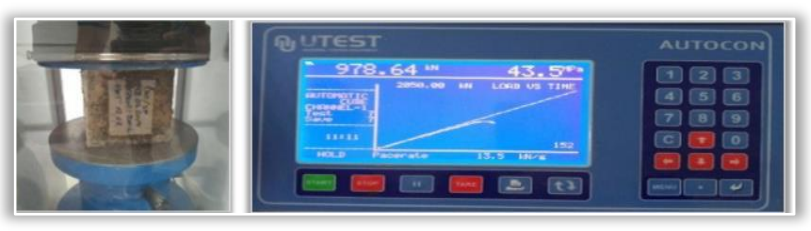

Figure 11. Compression strength test of with PET chips' reinforced concrete samples

Table 1. Experimental values - Table synthesis

\begin{tabular}{|c|c|c|c|c|c|}
\hline \multirow{2}{*}{ No. experiment } & Characteristics & \multicolumn{4}{|c|}{ Experimental values } \\
\cline { 2 - 6 } & Breaking force, $[\mathrm{kN}]$ & 906 & 908 & 886 & Average value \\
\hline \multirow{2}{*}{$\begin{array}{c}\text { Experiment no.1: } \\
\text { Concrete samples } \\
\text { (etalon) }\end{array}$} & Compression strength, $[\mathrm{N} / \mathrm{mm} 2]$ & 40.3 & 40.4 & 39.4 & 400 \\
\cline { 2 - 6 } & Mass of the samples, $[\mathrm{kg}]$ & 7.90 & 7.98 & 8.01 & 7.96 \\
\cline { 2 - 6 } & Density of concrete, $[\mathrm{kg} / \mathrm{m} 3]$ & 2341 & 2364 & 2373 & 2360 \\
\hline $\begin{array}{c}\text { Experiment no.2: } \\
\text { PET flat strips' } \\
\text { reinforced concrete } \\
\text { samples }\end{array}$ & Breaking force, $[\mathrm{kN}]$ & 1027 & 948 & 970 & 982 \\
\cline { 2 - 6 } & Compression strength, $[\mathrm{N} / \mathrm{mm} 2]$ & 45.6 & 40.8 & 43.1 & 43.19 \\
\cline { 2 - 6 } & Mass of the samples, $[\mathrm{kg}]$ & 8.10 & 8.15 & 8.20 & 8.15 \\
\hline $\begin{array}{c}\text { Experiment no.3: } \\
\text { PET chips' } \\
\text { reinforced concrete } \\
\text { samples }\end{array}$ & Density of concrete, $[\mathrm{kg} / \mathrm{m} 3]$ & 2400 & 2415 & 2430 & 2415 \\
\cline { 2 - 6 } & Breaking force, $[\mathrm{kN}]$ & 978 & 958 & 970 & 969 \\
\cline { 2 - 6 } & Compression strength, $[\mathrm{N} / \mathrm{mm} 2]$ & 43.5 & 42.6 & 43.1 & 43.05 \\
\hline
\end{tabular}

We have the following comments and remarks:

- The dispersed reinforced concrete samples were weighed to determine the densities of each (Figure 9). The average determined value of the density of concrete from class C30/37 was within the recommended range (between 2200-2400 kg/m ${ }^{3}$ ), being $2360 \mathrm{~kg} / \mathrm{m} 3$ (in the concrete sample), 2415 $\mathrm{kg} / \mathrm{m}^{3}$ (in the test with PET flat strips reinforcement), respectively $2410 \mathrm{~kg} / \mathrm{m}^{3}$ (in the test reinforced with PET chips) - Figure 12.

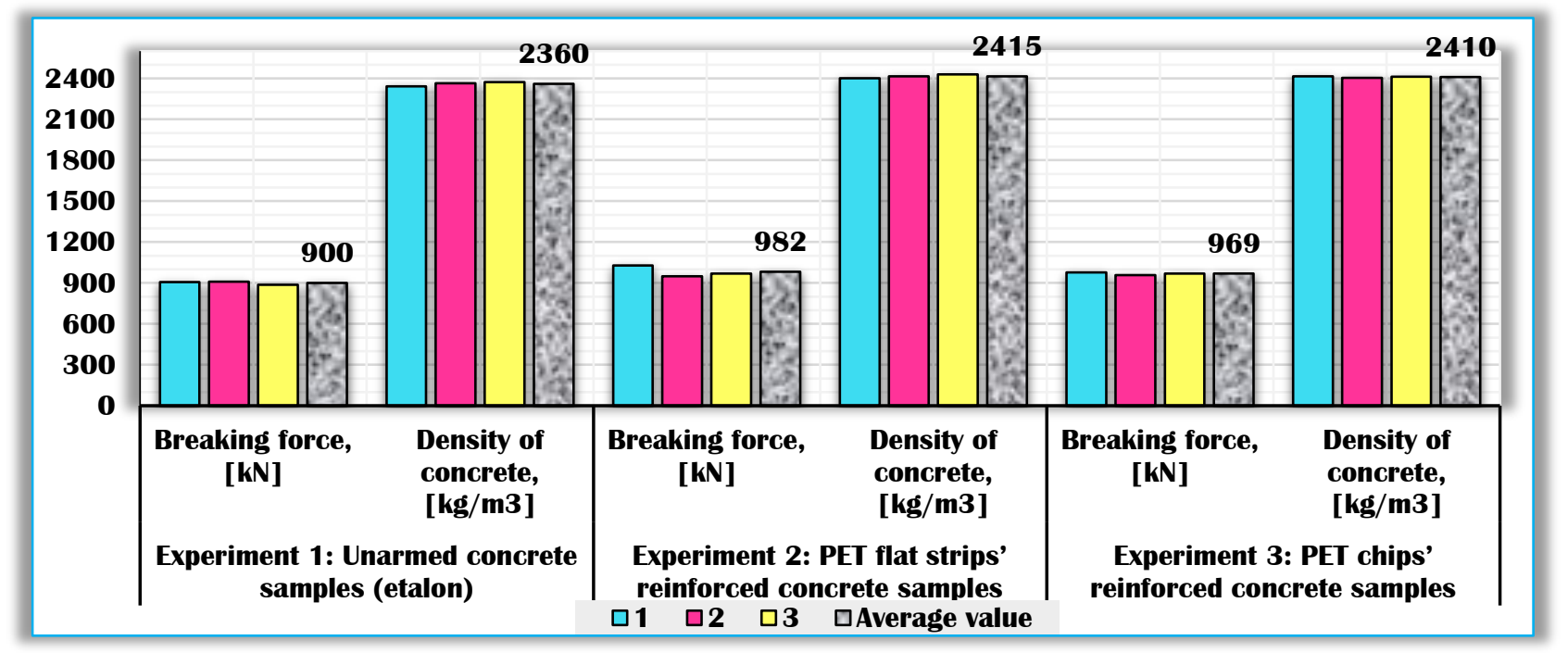

Figure 12. Breaking force and density of the concrete - Comparative study on the concrete samples, the PET flat strips' reinforced concrete samples and the PET chips' reinforced concrete samples 
- We started with the compression loading of the standard samples, with the average breaking force of $982 \mathrm{kN}$, resulting in an average resistance on the 3 samples of $40 \mathrm{~N} / \mathrm{mm}^{2}$ (Figure 12).

- The mass of the samples (with the nominal area $22500 \mathrm{~mm}^{2}, 150 \times 150 \mathrm{~mm}$ ) was $7.96 \mathrm{~kg}$ (in the concrete sample), $8.15 \mathrm{~kg}$ (in the test with polyethylene terephthalate flat strips reinforcement) respectively $8.13 \mathrm{~kg}$ (in the test with polyethylene terephthalate chips reinforcement) - Figure 13.

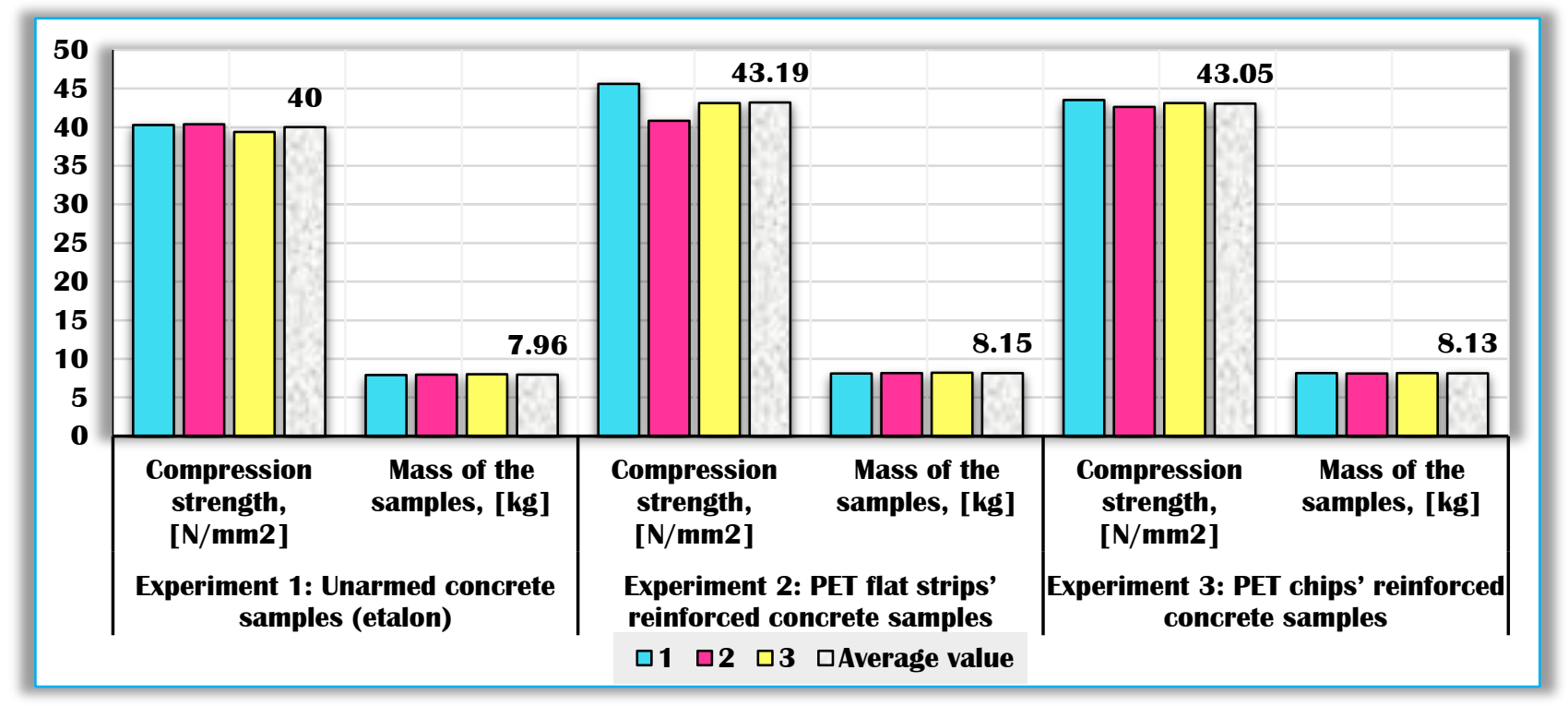

Figure 13. Compression strength and mass of the samples - Comparative study on the concrete samples, the PET flat strips' reinforced concrete samples and the PET chips' reinforced concrete samples

- Compression loading of the concrete samples reinforced with polyethylene terephthalate (PET) flat strips was performed with the average breaking force of $900 \mathrm{kN}$ (Figure 12). The results of the polyethylene terephthalate (PET) flat strips reinforcement were satisfactory because, with an average of the 3 tested samples, it showed an improvement of $3.19 \mathrm{~N} / \mathrm{mm}^{2}$, more precisely a total resistance of $43.19 \mathrm{~N} / \mathrm{mm}^{2}$ (Figure 13), an increase of $9.2 \%$ compared to the standard base samples of the matrix concrete class $\mathrm{C} 30 / 37$. One of the samples even registered a resistance related to the next class of concrete strengths, more precisely $45.6 \mathrm{~N} / \mathrm{mm}^{2}$ (equivalent of concrete C35/45).

- Compression loading of the concrete samples reinforced with polyethylene terephthalate (PET) chips was performed with the average breaking force of $969 \mathrm{kN}$ (Figure 12). The average resistance obtained for the reinforcement with polyethylene terephthalate (PET) chips was $43.05 \mathrm{~N} / \mathrm{mm}^{2}$ (Figure 13), an increase of approximately $9 \%$ compared to the standard samples, comparable to the case of polyethylene terephthalate (PET) flat strips reinforcement. The increase is only $3.05 \mathrm{~N} / \mathrm{mm}^{2}$ compared to the base matrix, but given the easy and relatively short time of the reinforcement it can be mentioned that it is a good increase of resistance, with this increase the concrete being at the top of the strength of its class, almost of the immediately superior class as resistance.

\section{Conclusions}

Having in view the compressive strength experiments of the dispersed reinforced concrete reinforced with recycled polyethylene terephthalate (PET) flakes coming from post-consumer packaging wastes, presented above, we have the following conclusions:

- The resulting composite materials are high performance materials, which by combining the components, lead to the obtaining of products with superior properties, as shown by the results obtained in compression tests. The composites obtained behave very well in constructions as durable materials with high mechanical resistance to compression. The percentage increase compared to non- 
standard concrete reinforced with polyethylene terephthalate (PET) flat strips and polyethylene terephthalate (PET) chips is at least $9 \%$, which is a significant increase if we refer to the related minimum costs, the time to make the reinforcements, as well as the possibilities of reusing the waste of polyethylene terephthalate (PET) packaging.

- Very low costs of polyethylene terephthalate (PET) reinforcement material recommend their use as reinforcement of concrete, and the methods do not require special equipment and machinery. Also, the reinforcement times are relatively small;

- Most PET bottles used as beverage containers become waste after their usage, causing environmental problems. To address this issue, a method to recycle wasted PET bottles is presented, in which short fibers made from recycled PET are used within structural concrete. To verify the performance capacity of recycled PET fiber reinforced concrete, it was compared with reinforced concrete;

- Both processes for achieving the reinforcement of concrete with polyethylene terephthalate (PET) reinforcement can be easily automated, through a simple weighing-dosing system, placed above the casting formwork or directly in the mixer. For mass production, with in-line automation of all processes (including reinforcement dosing), the supply of reinforcement to one cubic meter of concrete can be increased, which means a decrease in the prices of dispersed reinforced concrete production;

We conclude that these experiments must be continued. Specifically, we propose an analysis of the methods of reinforcement with polyethylene terephthalate (PET) flat strips and chips on different concrete matrices (different classes) and different contributions of dispersed reinforcement ( 3 and 5\%), to determine the optimal percentage of reinforcement required to improve the strength of these concretes. Also, we must propose a comprehensive analysis of the different dimensions of polyethylene terephthalate (PET) chips and flat strips. We believe that reinforcement can give better results to other dimensions of reinforcement elements (i.e. smaller fibre sizes, but more pieces).

These polyethylene terephthalate (PET) reinforcement materials can also take different shapes and sizes, such as braids (strands), in the form of plastic nets, but also three-dimensional. We also propose the use of other types of reinforcement, such as braided strands and braided mesh made from polyethylene terephthalate (PET) threads, analysing the behaviour of reinforced concrete dispersed with fibres during compression tests. In this case, experiments are also required for the stretching load (which is better suited).

\section{References}

1.SULYMAN, M., HAPONIUK, J., FORMELA, K., Utilization of recycled polyethylene terephthalate (PET) in Engineering Materials: A Review, International Journal of Environmental Science and Development, 7(2), 2016, pp. 100-108

2.SHAHIDAN, S., RANLE, N.A., MOHD ZUKI, S.S., SHEIKH KHALID, F., RIDZUAN, M., NAZRI, F.M., Concrete incorporated with optimum percentages of recycled polyethylene terephthalate (PET) bottle fiber, International Journal of Integrated Engineering, 10(1), 2018, pp. 1-8

3.THORNEYCROFT,_J., ORR, J., SAVOIKAR, P., BALL, R.J., Performance of structural concrete with recycled plastic waste as a partial replacement for sand, Construction and Building Materials, 161, 2018, pp. 63-69

4.OCHI, T., OKUBO, S., FUKUI, K., Development of recycled PET fiber and its application as concretereinforcing fiber, Cement and Concrete Composites, 29(6), 2007, pp. 448-455

5.KIM, S.B., YI, N.H., KIM, H.Y., KIM, J.H.J., SONG, Y.C., Material and structural performance evaluation of recycled PET fiber reinforced concrete, Cement and concrete composites, 32(3), 2010, pp. 232-240

6.FOTI, D., Use of recycled waste pet bottles fibers for the reinforcement of concrete, Composite Structures, 96, 2013, pp. 396-404

7.CHOWDHURY, S., MANIAR, A.T., SUGANYA, O., Polyethylene Terephthalate (PET) waste as building solution, International Journal of Chemical, Environmental \& Biological Sciences, 1(2), 2013, pp. 308-312 
8.VISHNU, A., MOHANA, V., MANASI, S., PONMALAR, V., Use of polyethylene terephthalate in concrete - A brief review, International Journal of Civil Engineering and Technology, 8(8), 2017, pp. 279-282

9.SHARMA, R., PAL BANSAL, P., Use of different forms of waste plastic in concrete - A review, Journal of Cleaner Production, 112(1), 2016, pp. 473-482

10.MITELEA, I., VARZARU, N., BORDEASU, I., POPESCU, M., Failure analysis of high frequency welding fixed joints of thermoplastic polymers. Mater. Plast., 46(4), 2009, 439-443

11.BORDEASU, I., MITELEA, I., LAZAR, I., MICU, L., M., KARANCSI, O., Cavitation erosion behaviour of cooper base layers deposited by HVOF thermal spraying, Rev. Chim., 68(12), 2017, 2914-2917

12.MICU, L. M., LAZAR, I., CIRCIUMARU, A., BORDEASU, I., PIRVUlESCU, L. D., HLUSCU, M., New results regarding cavitation behavior of polymers modified with anorganic substances coated on bronze surfaces. Mater. Plast., 55,(3), 2018, 460-463

13.LAZAR, I., BORDEASU, I., CIRCIUMARU, A., MITELEA, I., BOCII, L. S., Behavior of polymer thin films deposed on bronze surfaces at cavitation erosion, Rev. Chim., 69(10), 2018, 2921-2927

14.TUDOSE, V., TUDOR, D. I., GHEORGHIU, H., GHIBAN, N., Comparative analysis of the mechanical behaviour of optical sighting devices made of plastic or metallic materials, Mater. Plast., 50(4), 2013, 319-322

15.TUDOR, D. I., PETRESCU, H., HADAR, A., ROSU, A., Computer tomography investigation of defects in plastic material plates. Mater. Plast., 49(2), 2012, 123-128

16.BEJ, A., BORDEASU, I., MILOS, T., BADARAU, R., Considerations concerning the mechanical strength of wind turbine blades made of fiberglass reinforced polyester. Mater. Plast., 49(3), 2012, 212-218

17.MITELEA, I., VARZARU, N., BORDEASU, I., POPESCU, M., The high frequency welding aptitude of thermoplastic polymers, Mater. Plast., 46(1), 2009,101-107

18.TUDOR, D. I., PARAUSANU, I., HADAR, A., Validation of models of plates with discontinuities made of plastic materials, through modal analysis, Mater. Plast., 49(3), 2012, 166-170

19.GOANTA, V., HADAR, A., LEITOIU, B., Experimental procedure designed to determine the elastic characteristics of fiber-reinforced polymeric composite materials, Mater. Plast., 47(4), 2010, 450-456

20.FOTI, D., Preliminary analysis of concrete reinforced with waste bottles PET fibers, Construction and building materials, 25(4), 2011, pp. 1906-1915

21.PELISSER, F., MONTEDO, O.R.K., GLEIZE, P.J.P., ROMAN, H.R., Mechanical properties of recycled PET fibers in concrete, Materials Research, 15(4), 2012, pp. 679-686

22.KIM, J.H.J., PARK, C.G., LEE, S.W., WON, J.P., Effects of the geometry of recycled PET fiber reinforcement on shrinkage cracking of cement-based composites. Composites Part B: Engineering, 39(3), 2008, pp. 442-450

23.***SR EN 12390-7:2009, Test on reinforced concrete. Part 7: Reinforced concrete density (Încercare pe beton întărit. Partea 7: Densitatea betonului întărit)

24.***SR EN 12390-1:2013, Test on reinforced concrete. Part 1: Shape, dimensions and other conditions for specimens and patterns (Încercare pe beton întărit. Partea 1: Formă, dimensiuni şi alte condiţii pentru epruvete şi tipare)

25.***SR EN 12390-3:2009, Test on reinforced concrete. Part 3: The compressive strength of the specimens (Încercare pe beton întărit. Partea 3: Rezistenta la compresiune a epruvetelor)

$\overline{\text { Manuscript received: } 5.02 .2020}$ 